\begin{tabular}{|c|c|c|}
\hline & $\begin{array}{c}\text { European Association for the } \\
\text { Development of Renewable Energies, Environment } \\
\text { and Power Quality (EA4EPQ) }\end{array}$ & $\begin{array}{l}\text { International Conference on Renewable Energies and Power Quality } \\
\text { (ICREPQ'12) } \\
\text { Santiago de Compostela (Spain), 28th to 30th March, } 2012\end{array}$ \\
\hline
\end{tabular}

\title{
Input Current Distortion and Output Voltage Regulation of the Boost PFC Converter Operating with Different Control Methods
}

\author{
António P. Martins ${ }^{1}$ and António M. Cardoso ${ }^{2}$ \\ ${ }^{1,2}$ Department of Electrical and Computer Engineering \\ Faculty of Engineering, University of Porto \\ Rua Dr Roberto Frias, s/n, 4200-465 Porto, (Portugal) \\ Phone/Fax number: +351 225081816, e-mail: ajm@fe.up.pt
}

\begin{abstract}
There are many possible topologies for implementing power factor correction converters. Due to its advantages, the average current control method is one of the most widely used. The critical conduction mode control method is also very used and is employed here for comparison purposes. The main issues to be analyzed in the paper are the input current wave shape and the output voltage regulation. Simulation and experimental results are presented and discussed.
\end{abstract}

\section{Key words}

Current distortion, PFC control, Voltage regulation

\section{Introduction}

The proliferation of low power electronic equipment is here to stay. Usually, this equipment is supplied by the mains grid through a low power rectifier. Conventional, but still very used, power supplies based on uncontrolled AC/DC converters draw a non-sinusoidal current from the mains. They are very cheap and robust and belong to a special classification class in harmonic limiting standards, [1]. However, there are many important disadvantages in this topology: harmonic currents generate harmonic voltages that can interfere with electrical equipment; harmonic currents avoid the extraction of maximum power from the utility line. In addition, a large number of low power units connected to the same power line originate an important power demand with a strong nonlinear behavior. Unity power factor converters eliminate these shortcomings. The use of boost converter based power factor correction systems are increasing with the adoption of more severe standards covering (and reducing) the permitted level of harmonics injected into the utility.
There are many possible topologies for implementing unity power factor converters: single-stage single-switch controlled (boost, buck, buck-boost), flyback, Cuk, Sepic, and others, [2]. Being more simple and more widely used, the paper focus its attention in the boost controlled one [3]. Inside this topology the main control methods are: average current control, [3]-[4]; current-programmed control, [5]; hysteretic control, [6], critical conduction mode, [7], and predictive current control, [8]. The main difference between them is the way the input current is controlled. All these control methods can be implemented by commercially available ICs. In spite of this, there is a growing attention to the implementation of advanced digital controllers capable of outperform the analog based ICs, [9]-[11]. No matter the particular control method, the PFC system is always controlled under the diagram shown in Fig. 1. In order to obtain an acceptable output voltage dynamics with a continuous and sinusoidal input current a nested loop control structure with very different dynamics is needed.

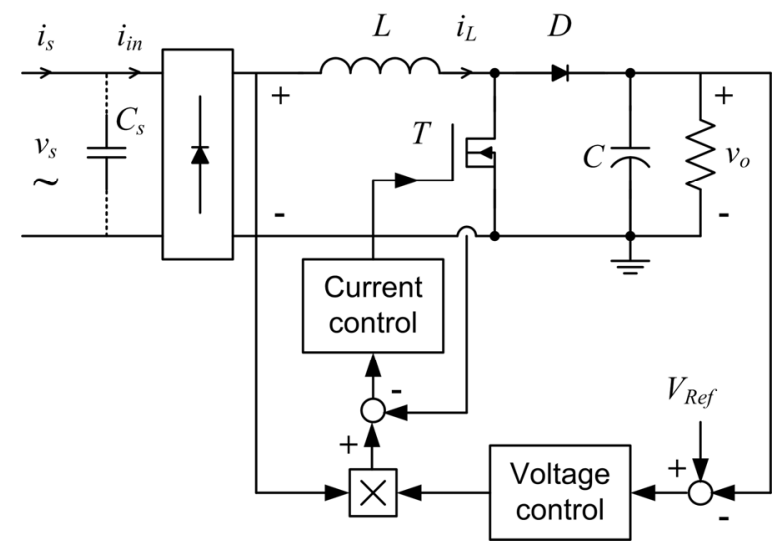

Fig. 1. Main control diagram of the boost PFC. 


\section{Controlling the PFC Converter}

The PFC controller should be designed in order to satisfy the following main electrical objectives: sine wave input current, without zero crossing distortion and high frequency harmonics, and unity power factor; fast output voltage dynamic response without an extremely high DC capacitor; variable input voltage compensation. All the referred controllers can satisfy these requirements, based on analog IC controllers or on its digital competitors. The main questions to discuss are the output voltage dynamics, the current controller performance, and the low frequency input current wave shape.

\section{A. Output Voltage Dynamics}

The PFC system is a non-reversible power circuit so its behavior is different when subjected to different conditions namely in a high negative step load change. In this case, the energy stored in the inductance is transferred to the output capacitor originating an over voltage.

The DC output voltage has an associate ripple imposed by the input pulsating power, and can not be eliminated without distorting the input current. So, this ripple must be filtered before entering the output voltage controller. The direct filtering can limit the voltage controller dynamics. In order to avoid this limitation two main approaches are possible: to introduce a notch filter tuned at twice the line frequency, [12]; to estimate the ripple voltage and subtract it from the measured DC voltage. A typical transfer function of the notch filter is:

$$
F_{N}(s)=\frac{s^{2}+\omega^{2}}{s^{2}+s \cdot \omega / Q+\omega^{2}}
$$

It is necessary to have a high $Q$ and the filter tuned exactly. If these conditions are not met, the filter performance deteriorates very quickly. As the ripple voltage is only approximated by the second harmonic term, other components enter the voltage controller which when multiplied by the input voltage will be propagated to the reference current, so increasing its distortion, as referred in the next section. Also, in fast dynamic changes the notch filter has a time response not particularly suited for this application.

Assuming a sine wave input current with unity power factor, the instantaneous input power is given by:

$$
p_{\text {in }}(t)=\sqrt{2} V_{S} \sin (\omega t) \sqrt{2} I_{S} \sin (\omega t)=V_{S} I_{S}-V_{S} I_{S} \cos (2 \omega t)
$$

The input power is the sum of the active power plus the pulsating power at twice the line frequency. Considering a lossless converter and a high switching frequency the instantaneous input power is approximately the same at the output stage. So, the instantaneous output power is the sum of the active load power plus the pulsating capacitor power. Neglecting the power associated with the ripple voltage and the ripple current it is obtained:

$$
p_{o}(t) \cong\left(V_{o}+v_{o}\right) I_{o}+C \frac{d v_{o}}{d t}\left(V_{o}+v_{o}\right) \cong V_{o} I_{o}+C \frac{d v_{o}}{d t} V_{o}
$$

Since

$$
V_{s} I_{S}=P_{o}=V_{o} I_{o}
$$

it results:

$$
C \frac{d v_{o}}{d t} V_{o}=-P_{o} \cos (2 \omega t)
$$

Solving for the ripple voltage:

$$
v_{o}(t)=-\frac{I_{o}}{2 \omega C} \sin (2 \omega t)
$$

The estimated ripple voltage is subtracted from the measured DC voltage in order to allow a higher bandwidth in the voltage controller. To implement this compensation term it is needed three elements: a sine wave of twice the fundamental frequency, which is usually implemented with a PLL, the output capacitor value, and the load current.

The estimation method based on (6) depends on the output capacitor value. When the PFC output terminals are connected to an unknown input stage, care must be taken in order to prevent the presence of an input capacitor of unknown value. In this case, the method can lead to an over estimation of the ripple voltage introducing a frequency component in the reference current that generates a distorted input current.

\section{B. Current Controller}

The presence and the importance of the current controller depend on each control principle. From the four ones considered here only the average current control method has it. The current-programmed control method has ramp compensation and a comparator; the hysteretic method doesn't have one; the critical conduction control method has a zero current detection. The typical transfer function of the current controller has a pole, which is placed below half the switching frequency, in order to filter out the inductor current ripple and a zero, to impose the desired bandwidth and phase margin of the current loop:

$$
G_{I}(s)=\frac{K\left(s+\omega_{z}\right)}{s\left(s+\omega_{p}\right)}
$$

The dynamics of the current controller is a very important issue, in order to guarantee a good tracking with the input voltage. It is the only way to obtain a sinusoidal wave shape with unity power factor.

\section{Input Current Behavior}

The pre-regulator circuits with unity power factor are primarily designed to present an input current almost sinusoidal. So, the most important parameter than should characterize each control philosophy is the low frequency harmonic content. This low frequency distortion has different causes: the reference current given by the voltage controller, the discontinuous inductor current near the zero crossings of the input voltage, the DC capacitor in the output of the diode bridge, or in the input EMI filter, [13]. 
The current zero-crossing distortion occurs in all methods with different importance. It can be only partially compensated [14]. In any configuration, the harmonic content is dependent on the load level, deteriorating at light loads, because of the longer intervals of discontinuous conduction.

\section{PFC Controller Performance}

To discuss the PFC performance under different operating conditions the following presented results were obtained in a system controlled by the Average Current Control method (ACC) and by the Critical Conduction Mode control method (CCM). Due to its advantages, the average current control method is one of the most widely used [15]. The critical conduction mode control method is also very used and is presented here for comparison purposes. The main issues to be analyzed are the input current wave shape and the output voltage regulation.

\section{A. At Full Load}

Full load is the main and more important operating point. In this condition the PFC converter is characterized in terms of input power factor, total harmonic distortion and efficiency. For demonstration purposes it was simulated a PFC converter with the following parameters: $V_{i n}=230$ $\mathrm{V}_{\mathrm{RMS}}, 50 \mathrm{~Hz} ; V_{o}=400 \mathrm{~V}_{\mathrm{DC}} ; P_{o}=400 \mathrm{~W} ; F_{c}=100 \mathrm{kHz}$; $L=1000 \mu \mathrm{H} ; C=330 \mu \mathrm{F}$. The current controller was designed to have the following parameters: $\omega_{z}=10 \mathrm{k} \cdot \mathrm{rad} / \mathrm{s}$; $\omega_{p}=20 \mathrm{k} . \mathrm{rad} / \mathrm{s} ; K=20.000$. It was used an input filter capacitor of $0.47 \mu \mathrm{F}$ in the ACC method and a $2 \mu \mathrm{F}$ capacitor in the CCM control method. In the critical conduction mode there is no current controller but the frequency has a maximum value of $100 \mathrm{kHz}$. In Fig.s 2 and 3 , it is shown the converter's operation at nominal power: input converter current and the output voltage ripple; in Fig.s 4 and 5, the low frequency spectrum of the input current for both control methods.

As can be concluded from the two figures, the ACC method leads to an input current with less high frequency distortion due to the half instantaneous inductance current.

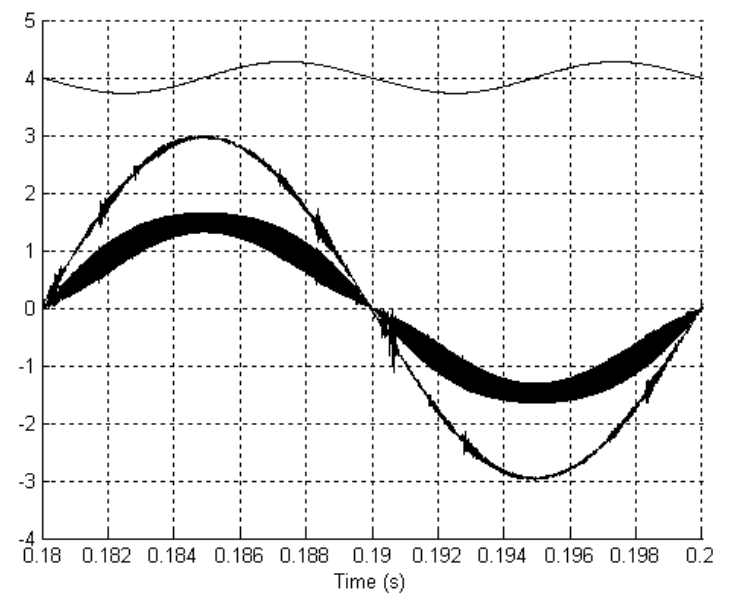

Fig. 2. ACC: output voltage $(20 \mathrm{~V} /$ div $)$, and converter input current before $(1 \mathrm{~A} / \mathrm{div})$, and after $(2 \mathrm{~A} / \mathrm{div})$ the input filter at nominal load $(400 \mathrm{~W})$.

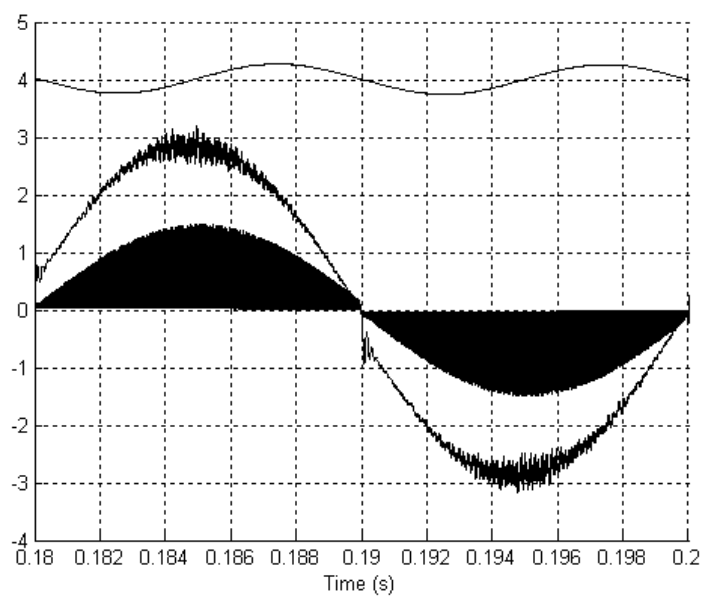

Fig. 3. CCM: output voltage $(20 \mathrm{~V} / \mathrm{div})$, and converter input current before $(1 \mathrm{~A} / \mathrm{div})$, and after $(4 \mathrm{~A} / \mathrm{div})$ the input filter at nominal load $(400 \mathrm{~W})$.

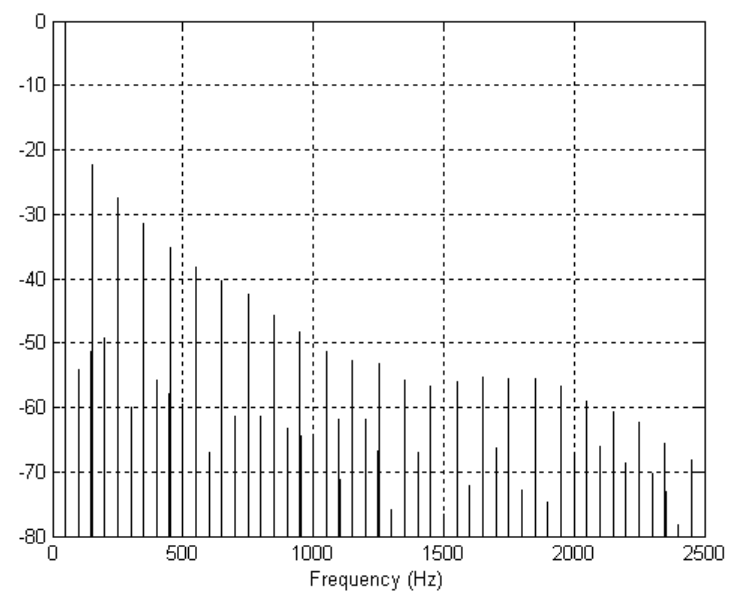

Fig. 4. ACC: low frequency spectrum of the input current at nominal load power (vertical scale in $\mathrm{dB}$ ).

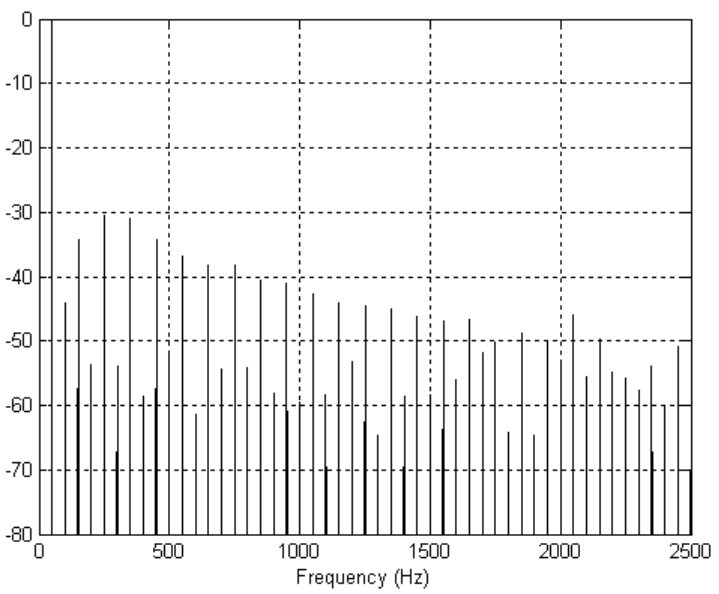

Fig. 5. CCM: low frequency spectrum of the input current at nominal load power (vertical scale in $\mathrm{dB}$ ).

\section{B. At Light Load}

As referred, the input current wave shape presents some degradation at light loads. This condition is not so important from the point of view of the grid interface. Classified as Class A or as Class D equipment, the input harmonic content is limited in absolute values, so at low power levels even a more distorted current easily satisfies the IEC 61000-3-2 standard. In Fig.s 6 and 7, it is shown 
the same waveforms for the two control methods. The input current spectrum when operating at light load (80 W) is shown in Fig.s 8 and 9.

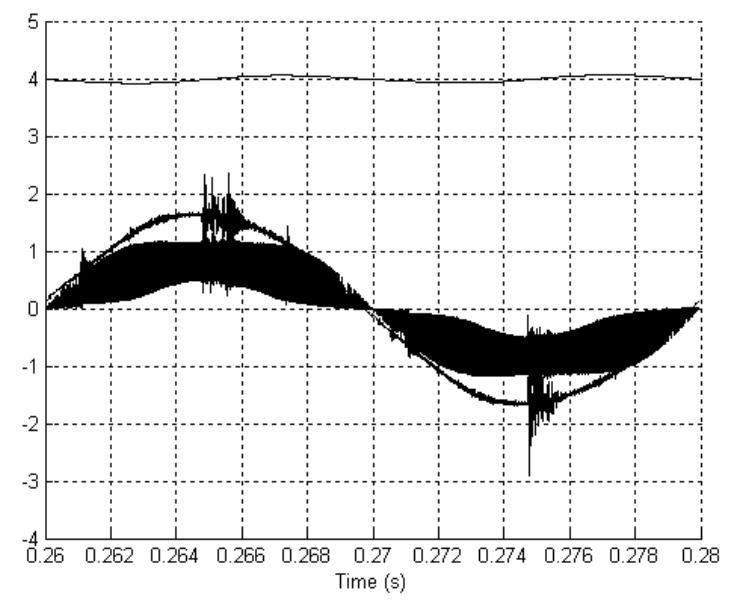

Fig. 6. ACC: output voltage $(20 \mathrm{~V} / \mathrm{div})$, and converter input current before $(0.5 \mathrm{~A} / \mathrm{div})$, and after $(1 \mathrm{~A} / \mathrm{div})$ the input filter at $20 \%$ nominal load.

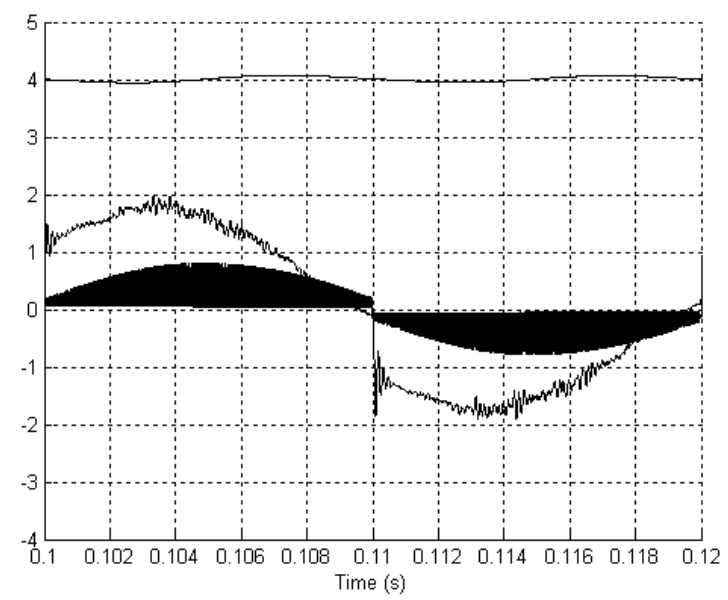

Fig. 7. CCM: output voltage $(20 \mathrm{~V} / \mathrm{div})$, and converter input current before $(0.5 \mathrm{~A} / \mathrm{div})$, and after $(2 \mathrm{~A} / \mathrm{div})$ the input filter at $20 \%$ nominal load.

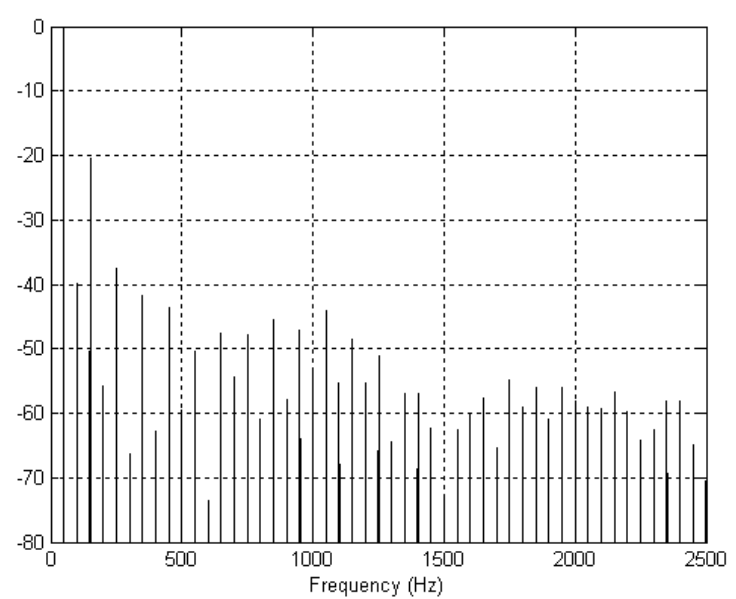

Fig. 8. ACC: low frequency spectrum of the input current at $20 \%$ nominal load (vertical scale in $\mathrm{dB}$ ).

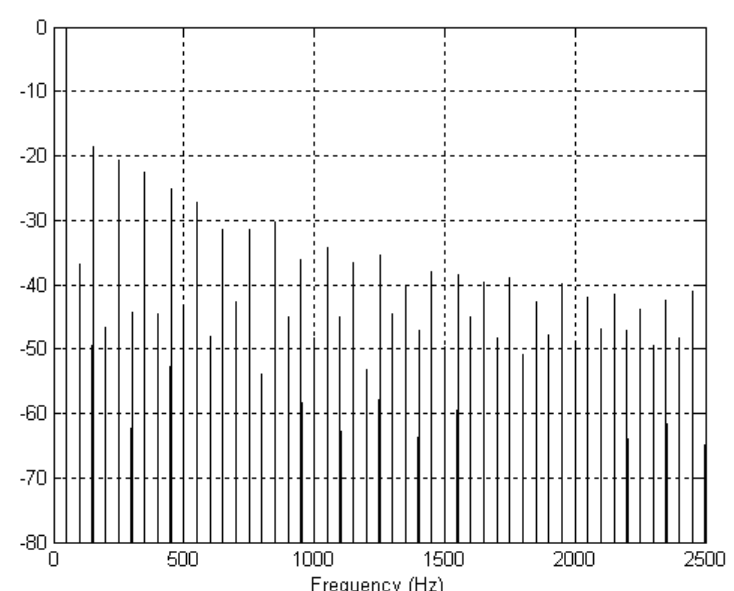

Fig. 9. CCM: low frequency spectrum of the input current at $20 \%$ nominal load (vertical scale in $\mathrm{dB}$ ).

As in the current waveform as in the low frequency spectrum there is a small degradation, especially in the CCM control method. Also, it is easy to conclude that the input power factor is less than one in this control mode. The presence of the input filter originates the small oscillations present in the input current, [16]. It should be mentioned that the other control methods all show equal or worse behavior than the ACC method or the CCM control method.

\section{Output Voltage Regulation}

As a pre-regulator circuit in the first stage of a power supply or as a stand alone regulated power supply, the boost PFC converter has a regulated output voltage. Usually, the voltage controller is of PI-type to assure voltage regulation and dynamics. As the PFC circuit is of non-reversible type there must be a compromise in the voltage controller design in order to give the voltage loop an over damped response. In this way the circuit maintains its "linear" behavior during the majority of the changing operating conditions.

In the two control methods presented here, the voltage controller exhibits the following parameters: $K_{p}=0.1$; $T_{i}=0.1 \mathrm{~s}$. The increased regulation dynamics was obtained through the use of a notch filter with $\omega=2 \pi 100 \mathrm{rad} / \mathrm{s}$ and $Q=10$.

Fig.s 10 and 11 present the dynamic output voltage regulation and input current variation during a load changing from $20 \%$ to $100 \%$ for the ACC method and the CCM control method, respectively. Also, they show the inductance and load currents during the same transient operation. The same waveforms can be seen in Fig.s 12 and 13 for a load changing from $100 \%$ to $20 \%$.

As the CCM control method implies an instantaneous inductance current of twice the ACC method this leads to a higher gain in the voltage controller, so conditioning the output voltage dynamics. In both conditions, at full load and light load, the ACC method has superior performance: the output voltage regulation is faster and the input current reaches earlier the sinusoidal waveform. 


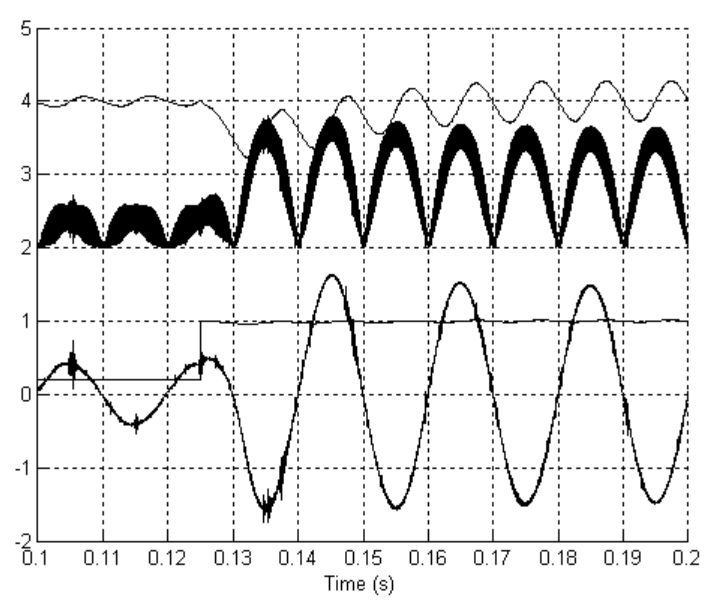

Fig. 10. ACC: output voltage $(20 \mathrm{~V} / \mathrm{div})$, inductance current $(2$ $\mathrm{A} / \mathrm{div})$, input current $(2 \mathrm{~A} / \mathrm{div})$ and load current $(1 \mathrm{~A} / \mathrm{div})$, during a step load change from $20 \%$ to $100 \%$.

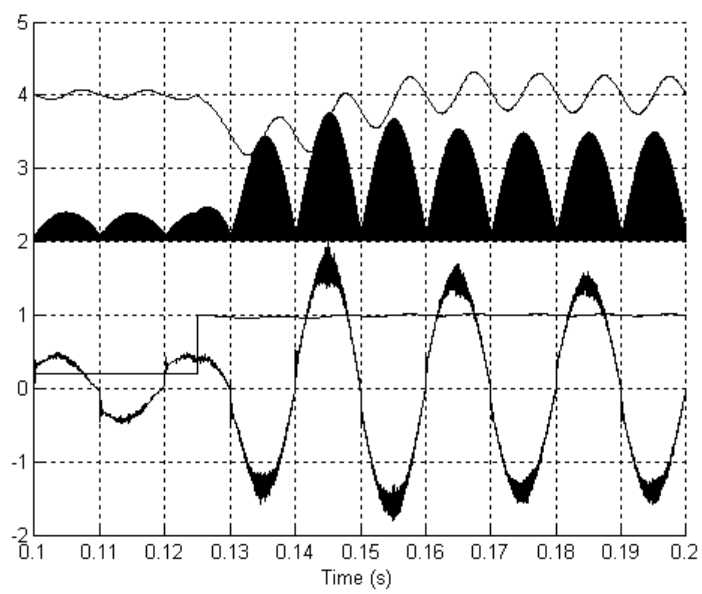

Fig. 11. CCM: output voltage (20 V/div), inductance current (2 $\mathrm{A} / \mathrm{div})$, input current $(2 \mathrm{~A} / \mathrm{div})$ and load current $(1 \mathrm{~A} / \mathrm{div})$, during a step load change from $20 \%$ to $100 \%$.

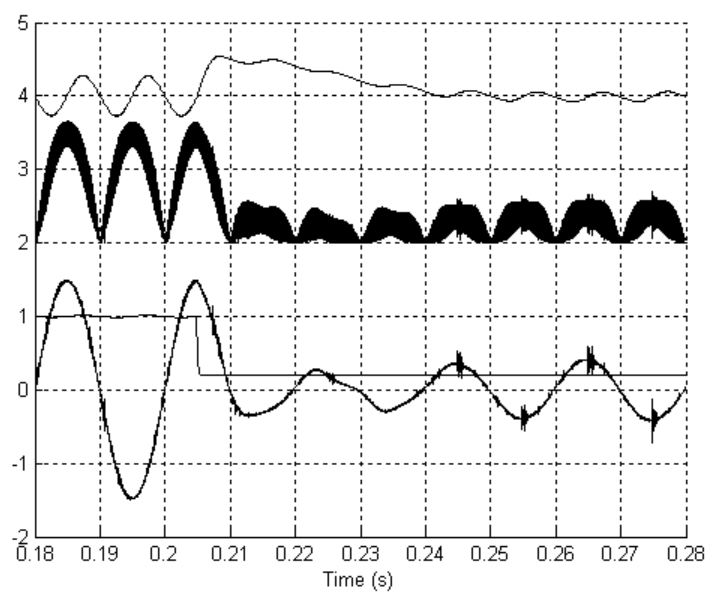

Fig. 12. ACC: output voltage $(20 \mathrm{~V} /$ div $)$, inductance current (2 $\mathrm{A} / \mathrm{div})$, input current $(2 \mathrm{~A} / \mathrm{div})$ and load current $(1 \mathrm{~A} / \mathrm{div})$, during a step load change from $100 \%$ to $20 \%$.

\section{Experimental Results}

A prototype was built and used for testing the two control modes. The operating condition shown in Fig.s 14 and 15, for average current control and for critical conduction control, respectively, corresponds to the nominal power and the same parameters used in the simulations. For demonstration purposes, a relatively large ripple in the DC current was imposed in the average current mode. In the critical conduction mode it can be noticed a larger influence of the inductor current ripple in the DC (and AC) voltage. The same behavior was already demonstrated in the simulations section, in Fig.s 2 and 3 respectively.

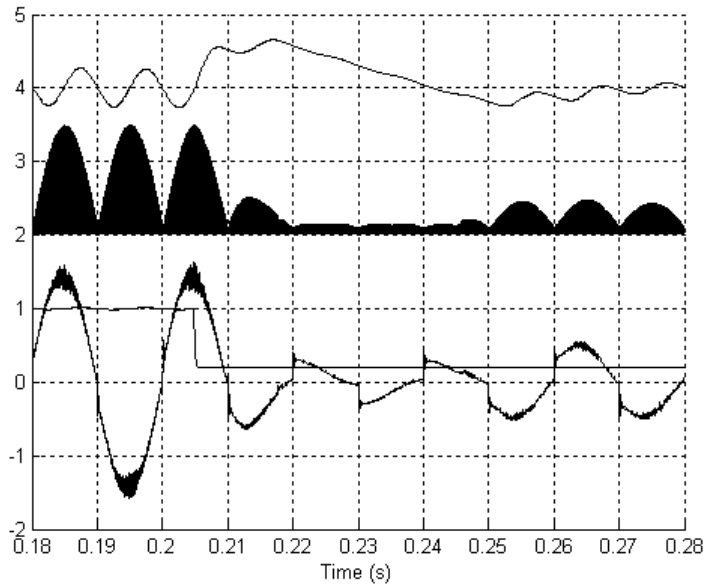

Fig. 13. CCM: output voltage (20 V/div), inductance current (4 $\mathrm{A} / \mathrm{div})$, input current $(2 \mathrm{~A} / \mathrm{div})$ and load current $(1 \mathrm{~A} / \mathrm{div})$, during a step load change from $100 \%$ to $20 \%$.

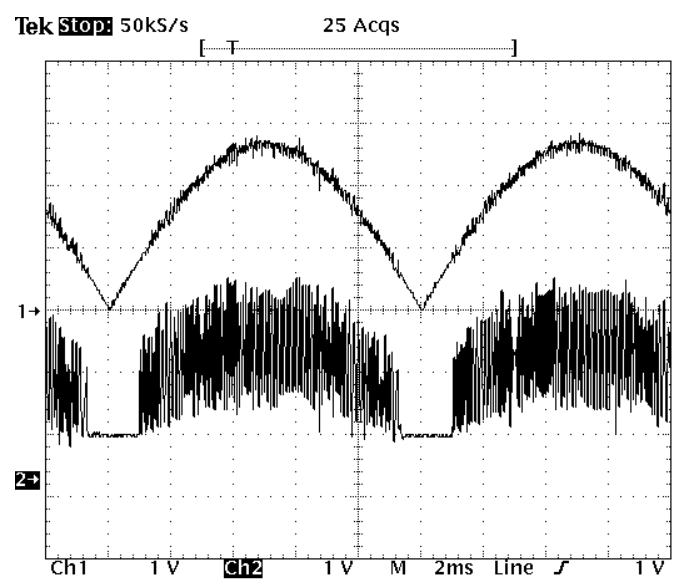

Fig. 14. PFC operation under average current mode: diode bridge output voltage $(120 \mathrm{~V} / \mathrm{div})$ and inductance current $(1 \mathrm{~A} / \mathrm{div})$.

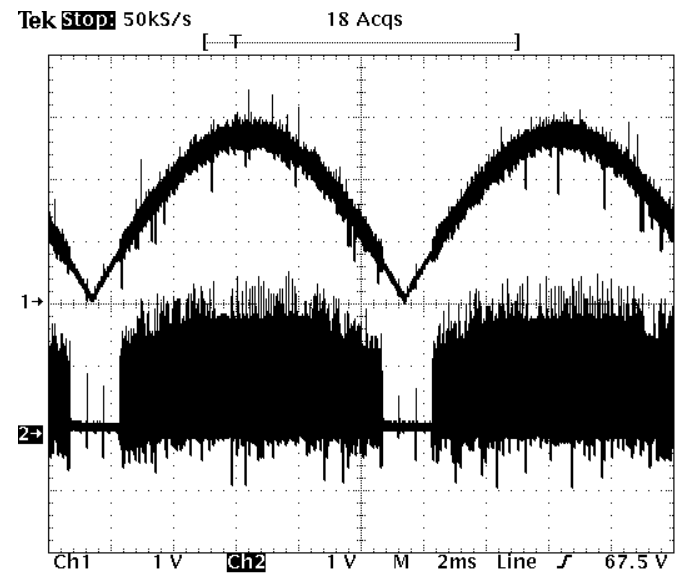

Fig. 15. PFC operation under critical conduction mode: diode bridge output voltage $(120 \mathrm{~V} / \mathrm{div})$ and inductance current (2 A/div). 


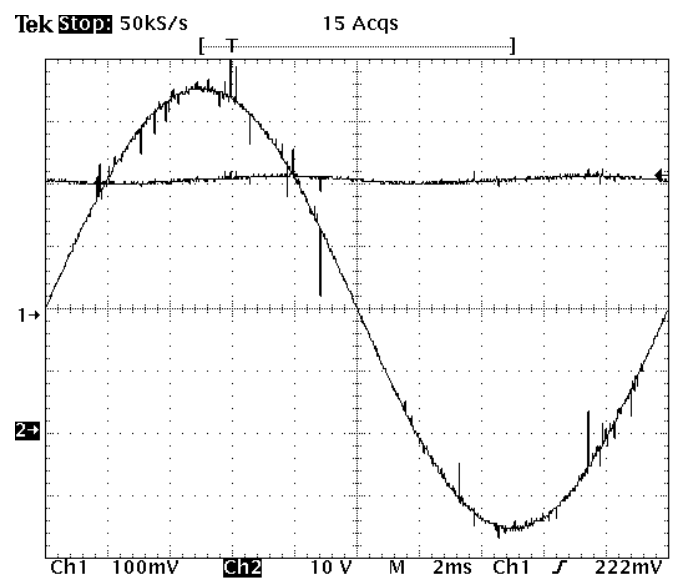

Fig. 16. Steady-state PFC operation under average current mode: input voltage $(\mathrm{Ch} 1: 100 \mathrm{~V} / \mathrm{div})$ and output voltage $(\mathrm{Ch} 2: 100$ V/div).

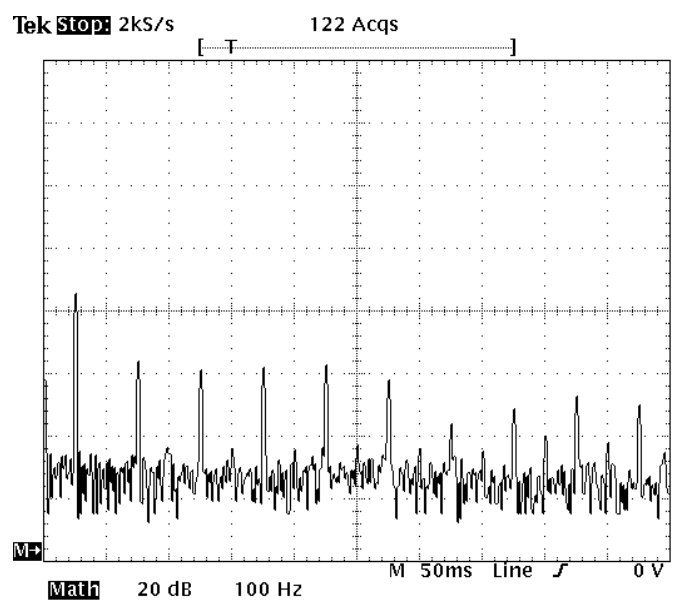

Fig. 17. Low-frequency harmonic components of the input current under average current mode.

As referred, the output voltage ripple does not depend of the current control method but on the capacitor value; its main variation is at twice the input frequency. Fig. 16 shows the AC input voltage and DC output voltage for the conditions in Fig. 14. In the same perspective, the influence of the DC voltage ripple is the occurrence of a third harmonic component in the $\mathrm{AC}$ input current. The $\mathrm{AC}$ current also contains odd multiples of the fundamental component due to some distortion around the zero crossings. This distortion can be observed in Fig. 17, for the average conduction mode, which shows the lowfrequency components of the input current.

\section{Conclusions}

The average current control method and the critical conduction mode control method for boost PFC converters were described, analyzed and compared. The fundamental issues regarding output voltage regulation and input current dynamics were discussed. Also, the low frequency spectrum of the input current, particularly at light loads, has been stated. The comparative results between the two methods show the superior performance of the average current control method. However, other parameters should be included in a global appreciation of the two methods like the semiconductor stress (transistor and diode), losses, measurement needs, EMI performance.

\section{References}

[1] International Electrotechnical Commission, "IEC 61000-32. Electromagnetic Compatibility (EMC): Limits for harmonic current emissions (equipment input current $<16$ A per phase)", 2005

[2] B. Singh, B.N.Singh, A. Chandra, K. Al-Haddad, A. Pandey, D.P. Kothari, "A review of single-phase improved power quality ac-dc converters", IEEE Transactions on Industrial Electronics, vol. 50 (5), pp. 962-981, Oct. 2003.

[3] Z. Yang, P.C. Sen, "Power factor correction circuits with robust current control technique", IEEE Transactions on Aerospace and Electronic Circuits, vol. 38 (4), pp. 12101219, Oct. 2002.

[4] P. Cooke, "Modeling average current mode control", in Proceedings of the Applied Power Electronics Conference, APEC, 2000, pp. 256-262.

[5] O. Dranga, C.K. Tse, H.H.C. Iu, I. Nagy, "Bifurcation behaviour of a power-factor-correction boost converter," International Journal of Bifurcations and Chaos, vol. 13, pp. 3107-3114, 2003

[6] S.-H. Li, C.-M. Liaw, "On the DSP-based switch-mode rectifier with robust varying-band hysteresis PWM scheme", IEEE Transactions on Power Electronics, vol. 19 (6), pp. 1417-1425, Nov. 2004.

[7] Y.-T. Chang, Y.-S. Lai, "Online parameter tuning technique for predictive current-mode control operating in boundary conduction mode", IEEE Transactions on Industrial Electronics, vol. 56 (8), pp. 3214-3221, Aug. 2009.

[8] J. Chen, A. Prodic, R.W. Erickson, D. Maksimovic, "Predictive Digital Current Programmed Control", IEEE Transactions on Power Electronics, vol. 18 (1), pp. 411419, Jan. 2003.

[9] W. Zhang, G. Feng, Y.-F. Liu, B. Wu, "A digital power factor correction (PFC) control strategy optimized for DSP", IEEE Transactions on Power Electronics, vol. 19 (6), pp. 1474-1485, Nov. 2004.

[10] P. Mattavelli, G. Spiazzi, P. Tenti, "Predictive digital control of power factor preregulators with input voltage estimation using disturbance observers", IEEE Transactions on Power Electronics, vol. 20 (1), pp. 140147, Jan. 2005.

[11] A. Prodic, J. Chen, D. Maksimovic, R.W. Erickson, "Selftuning digitally controlled low-harmonic rectifier having fast dynamic response", IEEE Transactions on Power Electronics, vol. 18 (1), pp. 420-428, Jan. 2003.

[12] A. El Aroudi, R. Haroun, A. Cid-Pastor, M. Orabi, L. Martinez-Salamero, "Notch filtering-based stabilization of PFC ac-dc pre-regulators", in Proceedings of the $14^{\text {th }}$ International Power Electronics and Motion Control Conference, EPE-PEMC 2010, pp. T13-22-T13-27.

[13] K.D. Gusseme, D.M. Van de Sype, A.P.M. Van den Bossche, J.A. Melkebeek, "Input-current distortion of CCM boost PFC converters operated in DCM", IEEE Transactions on Industrial Electronics, vol. 54 (2), pp. 858865, Apr. 2007.

[14] J. Sun, "On the zero-crossing distortion in single-phase PFC converters", IEEE Transactions on Power Electronics, vol. 19 (3), pp. 685-692, May 2004.

[15] R.W. Erickson, D. Maksimovic, "Fundamentals of Power Electronics", Kluwer Academic Publishers, 2001.

[16] J. Sun, "Input impedance analysis of single-phase PFC converters", IEEE Transactions on Industrial Electronics, vol. 20 (2), pp. 308-314, Mar. 2005. 